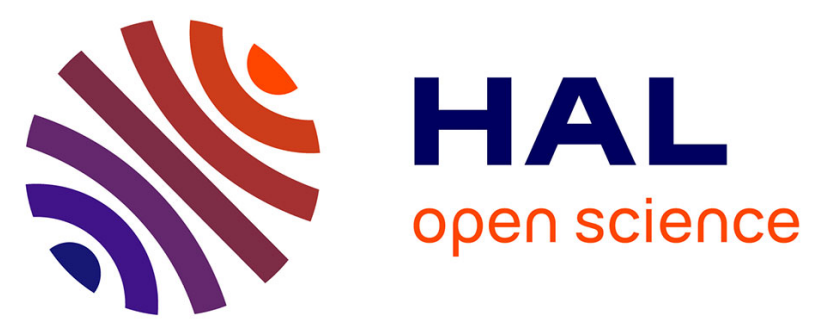

\title{
Influence of Starts and Stops on the Aging of Hydroelectric Generator Stators by Thermal Cycling: Empirical Study and Accelerated Lifetime Model
}

Olivian Savin, Carmen Badina, Jean-Louis Drommi, Julien Baroth, Sylvie

Charbonnier, Christophe Bérenguer

\section{To cite this version:}

Olivian Savin, Carmen Badina, Jean-Louis Drommi, Julien Baroth, Sylvie Charbonnier, et al.. Influence of Starts and Stops on the Aging of Hydroelectric Generator Stators by Thermal Cycling: Empirical Study and Accelerated Lifetime Model. ESREL 2021 - 31st European Safety and Reliability Conference, Sep 2021, Angers, France. pp.3214-3221, 10.3850/978-981-18-2016-8_315-cd. hal-03443019

\section{HAL Id: hal-03443019 \\ https://hal.science/hal-03443019}

Submitted on 23 Nov 2021

HAL is a multi-disciplinary open access archive for the deposit and dissemination of scientific research documents, whether they are published or not. The documents may come from teaching and research institutions in France or abroad, or from public or private research centers.
L'archive ouverte pluridisciplinaire HAL, est destinée au dépôt et à la diffusion de documents scientifiques de niveau recherche, publiés ou non, émanant des établissements d'enseignement et de recherche français ou étrangers, des laboratoires publics ou privés.

\section{(ㅇ)(1) $\$$}

Distributed under a Creative Commons Attribution - NonCommercial - NoDerivatives $\mid 4.0$ 


\title{
Influence of Starts and Stops on the Aging of Hydroelectric Generator Stators by
} Thermal Cycling: Empirical Study and Accelerated Lifetime Model

\author{
Olivian Savin \\ General Technical Division, Électricité de France, F-3800 Saint Martin le Vinoux, France \\ Univ. Grenoble Alpes, CNRS, Grenoble INP, GIPSA-lab, F-38000 Saint Martin d'Hères, France \\ Univ. Grenoble Alpes, CNRS, Grenoble INP, 3SR, F-38000 Saint Martin d'Hères, France \\ E-mail: nicolae-olivian.savin@edf.fr
}

Carmen Badina \& Jean-Louis Drommi

General Technical Division, Electricité de France, F-38950 Saint Martin le Vinoux, France

E-mail: carmen.badina@edf.fr

Hydro Engineering Center, Electricité de France, F-73373, Le Bourget du Lac, France

E-mail: jean-louis.drommi@edf.fr

Julien Baroth

Univ.Grenoble Alpes, CNRS, Grenoble INP, 3SR, F-38400 Saint Martin d'Hères, France.

E-mail: julien.baroth@univ-grenoble-alpes.fr

Sylvie Charbonnier \& Christophe Bérenguer

Univ.Grenoble Alpes, CNRS, Grenoble INP, Gipsa-Lab, F-38400 Saint Martin d'Hères, France.

E-mail: sylvie.charbonnier@grenoble-inp.fr, christophe.berenguer@grenoble-inp.fr

Due to the deregulation of the energy market and the integration of renewable energies, hydropower plant operators are faced with an increasing number of start and stops and load changes that can reduce the life of equipment. This paper proposes to assess the influence of the start and stop cycles on the ageing of stators in hydroelectric generators. In a first step, different modes of generator degradation are identified. The most affected component by start and stop cycles is the stator insulation,because of the thermal stress induced by these cycles, and the insulation default is considered to be the first cause of a premature end-of-life. The stator lifetime is first estimated using a Weibull analysis on the winding replacement dates recorded on a large number of units subject to a variable number of start and stop cycles per day. The results show that there is a significant difference in lifetime between installations subject respectively to a high or a lower number of start and stop cycles. As the degradation of the generators' insulation is mainly due to thermal stress, a model using Coffin Manson's law is then used to explicitly take into account this stress and to determine the acceleration factor that allows predicting the reduction of the stator's lifetime due to thermal cycling. The proposed accelerated model is used on actual temperature monitoring data and the results show that the value of the acceleration factor is greater than one and increases with the cycles frequency which means that the life of the generator stator decreases as the number of starts and stops per day increases.

Keywords: hydroelectric generator, stator, start and stop, rewinding, lifetime, Weibull, thermal cycling, Coffin Manson

\section{Introduction}

The development and integration in the electrical grid of new types of energy create power fluctuations because of their intermittent character of operation. The hydro power plants are solicited to ensure the power system security and to maintain an appropriate level of quality of energy supplied to consumers. Consequently, they have to operate with a higher number of start and stop cycles, which induces additional damages, accelerates the degradation process and reduces the lifetime of the hydro power plant equipment. The generator is a very important and critical equipment of a hydro power plant, with a long service life but an unexpected winding failure can result in a machine shutdown of up to one year as Klamt et al. (2011) stated.

Different studies that estimate the damage, and then the additional induced cost, of a start and stop of a hydro power plant are presented in a literature

Proceedings of the 31th European Safety and Reliability Conference.

Edited by Bruno Castanier, Marko Cepin, David Bigaud and Christophe Berenguer Copyright (C) 2021 by ESREL2021 Organizers. Published by Research Publishing, Singapore ISBN: 981-973-0000-00-0 :: doi: 10.3850/981-973-0000-00-0_output 
review by Savin et al. (2020). Nilsson and Sjelvgren (1997) estimated that a unit abrasion caused by a single start and stop adds an equivalent operating time $\Delta \mathrm{d}=15$ hours of normal operation.In an earlier study, EPRI (1984) adopts a rule of thumb to attribute an equivalent of 10 normal operating hours per cycle. In these studies, the main impacted equipment was the generator. In another study presented by Milano (2012) from Bureau of Reclamation for CEATI mentions a major power equipment manufacturer of hydro generators and windings who stated that, for every start or stop, a winding (regardless of size/length) would loose 8 hours of life, i.e. 16 hours for a complete start/stop cycle. However, to the best of our knowledge, no published work addressed the issue of quantifying the damage incurred on the generator by start and stop sequences, and the associated costs. With this work, we aim at filling this gap, and we propose to investigate this issue by studying the effect of different start and stop cycle frequencies on the lifetime of the generator, and we adopt two complementary approaches. Using Weibull lifetime modelling, we first analyse empirically the historical failure data of hydro generators and we show that starts and stops have indeed an effect of their lifetime. Second, using monitoring data on the operating temperature of the generators, we develop an accelerated lifetime model integrating explicitly the thermal stress induced by the starts and stops, using the Coffin-Manson law.

This paper presents the ongoing work and our progress so far, and is organized as follows. In Section 2, we identify the most common failure modes and we review the existing methods to estimate the lifetime of hydro generators. Considering the most impacting failure mode, i.e. the stator winding insulation failure accelerated by thermal stress, in Section 3 we highlight the effect of start and stop using a Weibull lifetime analysis of historical failure data collected on hydro generators subject to different start and stop histories. In Section 4, we present the accelerated lifetime model, integrating the operating temperature and its variation as a covariate in order to link the start and stop cycles to the generator lifetime. We show how this predictive model can be used to estimate the effect of a modification of the frequency of starts and stops cycles on the generator lifetime, for up to 7 cycles per day.

\section{Generators deterioration and lifetime estimation}

In this section, based on a literature review, we report that the main failure mode of generators is related to the insulation deterioration of the stator, and we present the main generator lifetime models associated to this failure mode which is directly linked to the thermal stress, both through physicochemical and mechanical mechanisms.

\subsection{Main failure mode of generators}

Sumereder and Muhr (2005) discusses the issue of the estimation of the residual lifetime of the electric insulation system of generators, and categorizes the ageing stresses into 4 classes : Thermal, Electrical, Ambient (environmental) and Mechanical (TEAM) causes, which all have an effect on the insulation identified as the main failure cause. E-Cigre (2009) presents the detailed results of an investigation on 69 incidents in a fleet of generators over 10 years: more than half of the failed machines exhibited an insulation damage. M.Guerrero and I.Rivera (2005) classifies the defaults occurring on generators with stator winding defaults being the most common, and most often a severe major default. From his experience, $\mathrm{Mi}-$ lano (2016) concludes that "It is generally known and accepted that the primary end-of-life failure mode of stator windings is associated with insulation failure due to insulation deterioration." We conducted a study similar to the E-Cigre on 297 EDF generators from 1982 and 2006: almost half of the defaults $(44,4 \%)$ are related to the stator insulation, more than a quarter $(29,5 \%)$ to the rotor insulation and the remainder to different causes (loosening, poor electrical and mechanical connection, cracked short circuit ring, etc.), see Fig. 1]

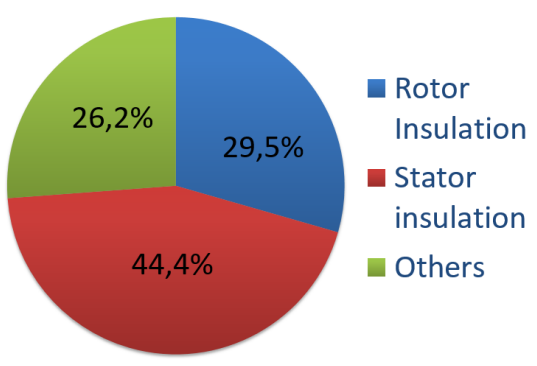

Fig. 1. Breakdown of the generators failure modes

Stone et al. (2009) pointed out the same most common generators problems as the one encountered at EDF. The other failures are related to external factors or manufacturing, installation, maintenance and are therefore not associated with loss of life due to normal aging processes and cycles (mechanical defects, fire, etc.).

Stator insulation damages appear as one of the failure causes for the hydro generator, and we focus in the next subsection on the generator lifetime modelling considering only this main driving fault. 


\subsection{Modelling and estimating the lifetime of generators: state-of-the-art}

One of the first papers for estimating the remaining life of insulation in rotating electrical machines adopts a Markov chain reliability model, Anders et al. (1990), which considers the evolution of deterioration from one state to another (new state, low deterioration, significant deterioration, insulation failure), assuming that the insulation system, if left unmaintained, will deteriorate in stages. One of the disadvantages of the method is to determine the condition and degree of deterioration; there is a need for similar machines (same producer, technology, design and operating conditions) and additional studies have to be carried out (e.g. with expert opinion or diagnostic tests - the latter possibility cannot be fully exploited due to the lack of instruments to monitor all important factors). Another disadvantage of the method is the determination of different transition rates between deterioration stages.

A post-processing statistical method on stator bar tests (with voltage variation) is presented by Cimino et al. (2020) in an attempt to estimate the insulation lifetime. Due to the limited amount of data (tests) that represents a disadvantage for this method, the bootstrapping technique is used as a statistical method that is based on random sampling with replacement where repeated statistics are calculated based on a single sample.

Accelerated aging tests in the laboratory presented by Stone et al. (1991), Morin et al. (1995), Brütsch et al. (2008) and Istad et al. (2011) showed a correlation between increasing thermal cycles and winding deterioration. For thermal aging, these accelerated tests established the "10degree rule": coil insulation life decreases by half for every $10^{\circ} \mathrm{C}$ increase. But experts question the results of such aging tests. Kokko (2010) in an experimental study found a difference between the results of the laboratory tests and stator windings that operate for a long time. He proposed a method to match generator test results (electrical, thermal, and mechanical), with the operating history of generators in service using the inverse power law from aging model presented by Montanari and Simoni (1993). One of the reasons for the experts' concern is that accelerated tests are usually performed for new windings under clean laboratory conditions. However, the operating conditions of real stator windings are often worse, which can lead to a weakening of the insulation properties. Other studies Bureau of Reclamation (2004) and Boucher (2010) suggest that deterioration may not be visible in the field because operating conditions are not as severe as those encountered in the laboratory and it is difficult to correlate test results with normal operation, therefore, expert opinion to interpret historical operating data, fault statistics, tests and optical investigations was necessary.
One of the most widely used models for the simulation and modeling of the aging mechanism relies on an inverse power law for electrical and mechanical aging and an Arrhenius law for thermal aging Kokko (2012). Based on the Simoni law (derived from the Coffin-Manson equation), which describes a model of deterioration of electrical resistance, the model used by Kokko (2011) integrates the thermal (temperature) and electrical (voltage) stresses.

Sumereder (2008) presents a statistical study to estimate the lifetime based on the failure probability and historical data with the Weibull distribution. In the paper, it was shown that it is very important and useful to collect operational data from the machines as it provides the information needed for lifetime statistics (e.g. rewindings years).

Sumereder and Muhr (2005) stated that models do not give immediate life expectancy and do not cover all deterioration phenomena (electrical, thermal and mechanical). These models and tests provide observations on the potential aging factors of stator windings and give an indication of the level of potential deterioration. Greisen and Norlin (2016) reviewed existing and available industry information/data and their relationship to start and stop cycles and suggested that additional research/testing are required to understand the effects of start and stop cycling. The objective of this work is to contribute to bridge this gap.

\section{Influence of start and stop cycles on the generators lifetime}

This section aims at analyzing the lifetime of hydroelectric generators subjected to different start and stop cycling so as to conduct a first investigation on how the lifetime can be shortened by start and stops. In the absence of "true" failure, the generator lifetime is defined as the time to the stator rewinding, ie to the most important maintenance operation performed on a generator, after which the generator is considered as refurbished. This investigation is based on a Weibull analysis of historical rewinding data on two groups of generators with different start and stop cycles history.

\subsection{Weibull reliability law}

We use the Weibull distribution with two parameters that is largely used in reliability theory and in high voltage engineering, Cygan and Laghari (1990), whose probability density function is given by:

$$
f(x ; \alpha, \beta)=\frac{\beta}{\alpha}\left(\frac{x}{\alpha}\right)^{(\beta-1)} e^{-\left(\frac{x}{\alpha}\right)^{\beta}}
$$

where $\beta>0$ is the shape parameter and $\alpha>0$ is the scale parameter of the distribution. 


\subsection{Lifetime estimation and comparison}

This compared lifetime estimation is based on historical data from generators of different models and operating at different powers, but for which it can be assumed that they have a priori equivalent lifetimes (hypothesis stated and validated by EDF experts). These generators can be classified into two groups, assumed to differ only by they cycling rate :

- Low cycled plants : run-of-rivers, small impoundment and diversion hydro power plants for which the average number of cycles is lower than one cycle per day.

- High cycled plants : diversion facilities and pump storage hydro power plants where the average number of cycles per day is two or sometimes more (the number of cycles per day represent the average from the commissioning until now).

Table 1 presents the data available for the population and both groups.

Table 1. Population data used to estimate the lifetime of the generators.

\begin{tabular}{llll}
\hline & $\begin{array}{l}\text { Low cycled } \\
\text { plants }\end{array}$ & $\begin{array}{l}\text { High cycled } \\
\text { plants }\end{array}$ & Total \\
\hline No. of generators & 299 & 43 & 342 \\
Rewound & 171 & 21 & 192 \\
Percentage (\%) & 57 & 49 & 56 \\
\hline
\end{tabular}

Figs. 2 and 3 show the lifetime histograms for the low cycled and high cycled generators, as well as the probability densities, fitted using a Weibull distribution. A right censoring Weibull estimation was performed to obtain these probability densities to integrate all the data in Table 1, even if they are right censored (a high proportion of generators were not rewound). The law was tested for a $99.9 \%$ confidence interval.

The average lifetime of the first group was estimated at 60 years, and at 50 years for the second group, showing an acceleration factor be-

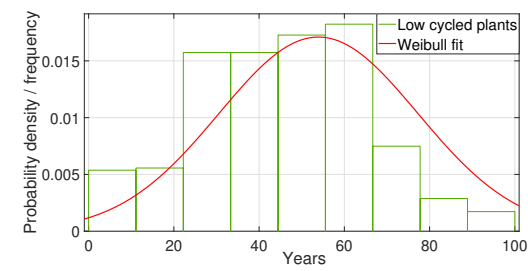

Fig. 2. Weibull distribution for low cycled generators

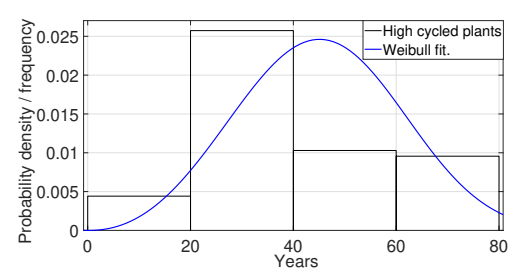

Fig. 3. Weibull distribution for high cycled generators

tween the groups equal to 1.2. The difference in lifetime comes mostly from the operating mode of the plants, and more particularly for the second group from the operation at an intensified start and stop frequency mode, which has an impact on the wear and tear of the equipment.The first histogram shows that a higher proportion of cycled power plants have been rewound at a older age, while the low cycle power plants at a younger age. Furthermore, the shape factor for the non cycled plants is equal to 3.2 and for the non-cycled plans is equal 2.4 meaning a faster ageing for the generators that experience more cycles per day.

\section{Estimation of the decrease of the generators lifetime due to thermal cycles induced by starts and stops}

\subsection{Starts and stops and temperature cycling}

Milano (2012) stated that winding stresses generated by temperature cycling represent one of the main cause of stator insulation deterioration, which induces a reduction in stator life. The analysis of temperature data from the on-line surveillance system of hydro power plants (data recorded at a sampling period of 10 minutes) clearly shows an evolution of the average temperature, the temperature range but also the cycling frequency as a function of the starts and stop cycles. This chapter deals with generators with a large number of cycles, among which are the pumped storage hydroelectric plants (PSPPs). We studied the temperature evolution of the pump storage generator. This choice was made because some PSPPs operate all or nothing only with the nominal power without power fluctuation, meaning that the temperature cycles have semi-sinusoidal shape that can be easier to analysis. Fig. 4 presents the joint evolution of the power and the temperature as a function of time.

Thermal cycling occurs when the generator starts and then stops. At start-up, once the generator is connected to the network, the temperature at the insulation rises due to thermoelectric stresses. After almost one hour, the temperature stabilizes and becomes constant during normal operation at its rated power. When the unit is disconnected from the grid, the temperature starts to gradually 

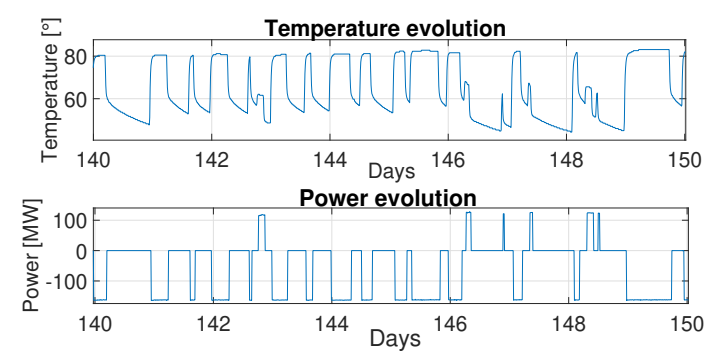

Fig. 4. Example of the evolution of temperature and power for a period of 10 days of a PSPP

decrease to the ambient temperature. For phases where the system is stopped for a long time, it takes several hours to cool down to ambient temperature. This is due to the fact that there is a fairly large heat store with a mass to cool the machine (can be up to 50 tons or even more). A distinction is made between pump mode and turbine mode. The range and the average temperature of a startup in pump mode is greater than the range and average temperature in turbine mode. Depending on the technology (design, power, cooling, etc.), the maximum temperature of the stator in pump mode can be between $70-90^{\circ} \mathrm{C}$ and when it stops, the temperature decreases to a temperature depending on the next stop. Therefore, at start-up, the temperature range can be around $20-50^{\circ} \mathrm{C}$ or even less, depending if the machine had time to cool down completely. The above analysis is done on a cycle in pump mode because of its high cycling frequency, average temperature and temperature range.

In order to model the lifetime of generators subject to starts and stops cycles, and hence to estimate the lifetime reduction due to temperature cycling, we propose to use an accelerated lifetime model, whose acceleration factor depends on the temperature. To this aim, we adopt the Coffin Manson model to represent the acceleration factor. The advantage of this model is that it takes into account the average temperature, as well as the frequency and the range of the cycles in temperature within the acceleration factor.

\subsection{Accelerated lifetime model}

Assuming that the influence of the system usage and environmental conditions modifies only the parameters of the system lifetime model, an accelerated lifetime model can be built in the following way, Hami et al. (2018). In the case of a Weibull lifetime law, denoting $R_{\text {nom }}($.$) the reliability under$ stress $x_{\text {nom }}$ (low cycled plants) and $R_{\text {acc }}($.$) the re-$ liability under stress $x_{\text {acc }}$ (high cycled plants), we have

$$
R_{\mathrm{acc}}(t)=R_{\mathrm{nom}}\left(t, \frac{\alpha}{A F}, \beta\right) \quad \text { and } \quad \alpha_{\mathrm{acc}}=\frac{\alpha}{A F}
$$

where $A F$ is the acceleration factor, which gives also directly the reduction factor of the average lifetime.

\subsubsection{Coffin Manson accelerated model}

Coffin Manson performed laboratory tests in the 50s and proposed an accelerated model to study the high temperature low cycle fatigue, Coffin (1953). The model is based on the Arrhenius equation which represents the most common acceleration law for an effect of temperature:

$$
\begin{aligned}
& A F\left(T_{0}, T_{1}\right)= \\
& \exp \left(\frac{E_{a}}{k}\left(\frac{1}{T_{0}}-\frac{1}{T_{1}}\right)\right)\left(\frac{\Delta T_{1}}{\Delta T_{0}}\right)^{p}\left(\frac{F_{0}}{F_{1}}\right)^{q}
\end{aligned}
$$

where

$T_{0}$ - temperature of base level [K]

$T_{1}$ - temperature of accelerated level [K]

$\Delta T_{0}$ - range temperature of base level

$\Delta T_{1}$ - range temperature of accelerated level

$F_{0}$ - cycling frequency of base level

$F_{1}$ - cycling frequency of accelerated level

$p$ - temperature range exponent

$q$ - cycling frequency exponent

$E_{a}$ - activation energy $[\mathrm{eV}]$

$k-$ Boltzmann constant $=8.6 \times 10^{-5} \mathrm{eV} / \mathrm{K}$

The typical values for Coffin Manson formula found in the literature (Cui (2005), NXP (1998)) for the exponent of the temperature range is $p=$ 1.9 and for the cycling frequency exponent is $q=$ -0.33 . Another unknown parameter is the activation energy, denoted $E_{\mathrm{a}}$. The activation energy reflects the average rate of chemical reactions that occur between cellulose and aging by-products (e.g., oxygen) and is affected by the moisture content of the insulation paper as Verma et al. (2017) stated. It can be determined by experiments by correlating the data and the model. In general, the values are between 0.3 - 1 (Hami et al. (2018)), depending on the material. However, for the majority of generators, impregnated epoxy resin is used and the values for this type of insulation are around 0.8 (Dixon (1980)). We adopt this value, assuming that it is not sensitive to temperature variations which concern us.

\subsection{Application to real monitoring data}

Using the monitoring data on the temperature of the stator insulation, and applying the Coffin Manson accelerated model, it is possible to estimate the lifetime reduction incurred by a given start 
and stop cycle. In this section, we illustrate the use of the Coffin Manson accelerated model to the generator of pumped storage hydroelectric plants for which monitoring data are available. The first step is to estimate the values of the variables $T_{0}$, $T_{1}, \Delta T_{0}, \Delta_{1}, F_{0}$ and $F_{1}$ from the monitored thermal cycling. The actual observed cycles in the monitoring data exhibit a high variability and can vary as a function of many factors like the season, the moment of start and the duration of functioning, the type of start (pump or turbine). Because of this high variability, it is difficult to determine these quantities directly, and we propose to resort to cycle modelling and simulation, either using cycle model learnt from the real data or directly simulating from pattern cycle extracted from the data. In the following, for illustration purposes, we consider two types of pump cycle: one with the same functioning duration independent of the cycle frequency, and one with a functioning period equal to the cooling period.

\subsubsection{Modelling and simulation a pump cycle}

When observing a typical one-day-period cycle, it can be seen that the temperature variation during start and stop occurs in two stages: the operation stage up to rated power and the cooling stage. We can thus represent this cycle using a piecewise polynomial model consisting of 5 polynomial equations of $1^{\text {st }}$ and $2^{\text {nd }}$ degree $(a, b, c, d$, e), which allows to better understand the dynamic of a cycle and eventually to simulate it. Fig. 5 represents the 5 phases of a typical cycle model.

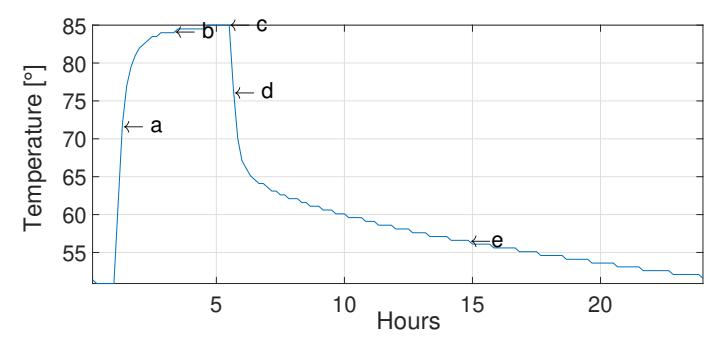

Fig. 5. Typical cycle decomposed in 5 phases for piece-wise polynomial modelling

Simulated pump temperature cycle with operating time equal to cooling time. In the first simulation, we create cycles with operating and cooling phases of equal duration. Thus, the daily operating time remains the same, regardless of the number of cycles performed. Only the cycling will have an effect on the temperature. Fig. 6 represents the simulated cycles (for 1,2,3,4,6 and 7 cycles per day) in different colors and with the red dotted line the cycle used to study the dynamics of the cycles, also displayed in figure 5 . It can be observed that an increased cycling frequency entails a higher average temperature and smaller temperature range.

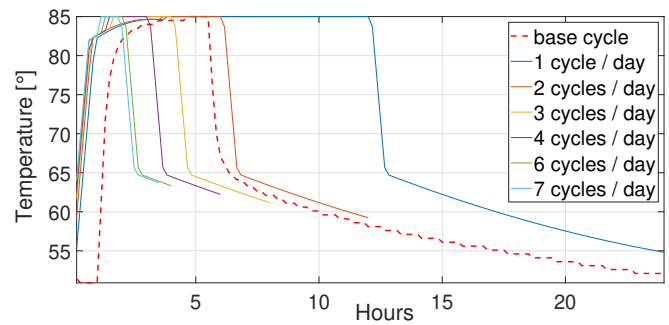

Fig. 6. Simulated cycles with equal operating and cooling time

Simulated pump temperature cycle with fixed operating time and a cooling time that decreases with cycling. For a second simulation, a representative temperature pump cycle was chosen and duplicated up to 5 cycles per day to estimate the average temperature and the temperature range and calculate the acceleration factor, when keeping the same nominal operating time. Thus, the duration of phase $c$ (nominal functioning) does not change, only the duration of phase $e$ (cooling time) changes, hence the operating time increases with the number of cycles. Fig. 7 represents the cycles : such a simulated operation corresponds to a scenario that is close to the real operation mode of the power plants where the operating time does not decrease with cycling.
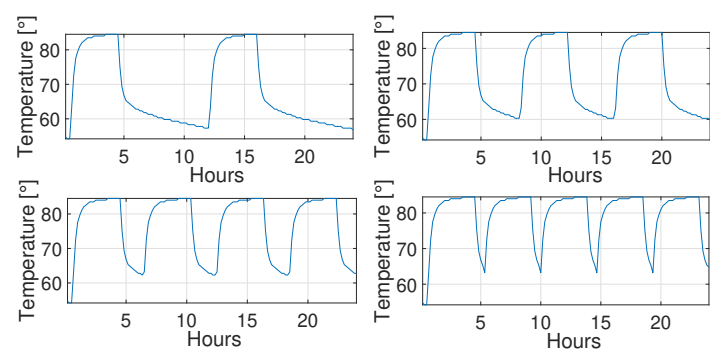

Fig. 7. Simulated cycles with the same operating time

\subsubsection{Coffin Manson accelerated factor for simulated cycles}

The results of the Coffin Manson accelerated factor are presented in Fig. 8 for both simulations.

We considered that the base level is equal to 1 cycle per day and we calculate the AF (Acceleration Factor) for a change from the base level to accelerated levels that are up to 7 cycles per 


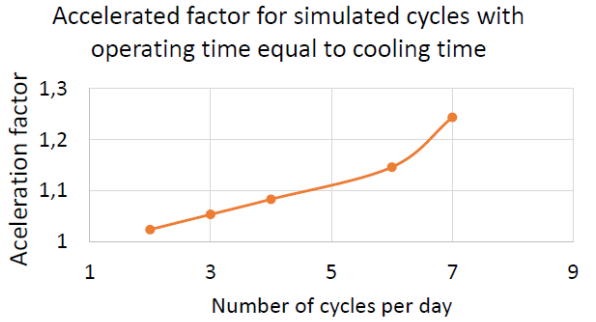

Accelerated factor for simulated cycles with the same operating time

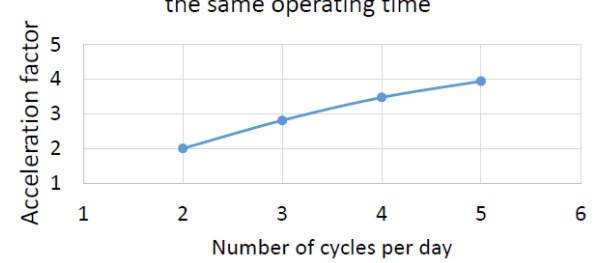

Fig. 8. Accelerated factor for simulated cycles

day (i.e. $\mathrm{F}_{0}=1, \mathrm{~F}_{1}=(1,2, \ldots, 7)$ with the associated average temperature and temperature range).

In the first case, the average temperature rises slowly from almost $72^{\circ} \mathrm{C}$ for one cycle per day to $75^{\circ} \mathrm{C}$ for 7 cycles per day and the temperature range drops from $30^{\circ} \mathrm{C}$ to almost $20^{\circ} \mathrm{C}$. The hypothesis that the operating period is equal to the cooling period has a less significant impact on the lifetime, with a reduced up to $20 \%$ of the lifetime for 7 cycles per day.

In the second case, the average temperature rises from almost $60^{\circ} \mathrm{C}$ for 1 cycle that lasts 24 hours to $80^{\circ} \mathrm{C}$ for 5 cycles per day of almost 5 hours each and the temperature range drops from $30^{\circ} \mathrm{C}$ to almost $20^{\circ} \mathrm{C}$. The fact that the operating period remains the same and only the cooling time decreases has an impact on the accelerated factor that can reach values up to 4 , meaning a lifetime reduced up to $75 \%$.

\section{Conclusion}

The effect of start and stop on the generators of a hydro power plant was investigated using two methods. The first method estimates the lifetime of generators using a Weibull analysis on historical lifetime data. Two groups have been created according to the number of cycles. This cycle estimation is done over the period of generator operation. On the considered example and set of data, the results show a decrease in life for cycled plants of about $17 \%$, representing only the result between the two considered groups and not a general one.

A second method is proposed with the CoffinManson accelerated life law. This predictive model calculates an acceleration factor as a function of temperature and number of cycles per day. While the first method estimate the lifetime for
1 and 2 cycles per day, the second method tries to model up to 7 cycles per day. The temperature of a pumped storage hydroelectric plants (PSPPs) is analyzed. Different factors were identified to influence the cycles temperature so two types of simulated cycles were created from a representative cycle to see the evolution of the acceleration factor. It could be observed that the lifetime follows the same trend as the one observed in the first investigation on historical lifetime data, which means that the lifetime decreases with increasing cycles. The influence of cycles was also shown using a Coffin-Manson model that represents a predictive model and shows how it could capture the effect of different cycling modes on the lifetime rather than fitting the real data to estimate a lifetime reduction on a real cycle.

Both methods show the decrease in lifetime due to start and stop cycling. The first method was conducted on the available data so far, a limited number of plants with an estimated number of cycles over the whole lifetime. More accuracy can be obtained with more plants. The second method was applied on the temperatures recorded over one year on one PSPP. The study can be extended to several years, more power plants and the turbine mode operation have to be integrated.

The proposed methodology can be used to estimate a cost per start-stop as a function of power and speed if the equipment purchase and maintenance price is known.

\section{References}

Anders, G. J., J. Endrenyi, G. L. Ford, and G. C. Stone (1990). A probabilistic model for evaluating the remaining life of evaluating the remaining life of electrical insulation in rotating machines. IEEE Transactions on Energy Conversion 5(4), 761-767.

Boucher, V. (2010). Etude du vieillissement de matériaux hautes températures pour machines tournantes et définition de méthodes d'essais accélérées. Thèse de doctorat, Université de Grenoble. [In French].

Brütsch, R., M. Tari, K. Fröhlich, T. Weiers, and R. Vogelsang (2008). Insulation failure mechanisms of power generators [feature article]. IEEE Electrical Insulation Magazine 24(4), $17-25$.

Bureau of Reclamation (2004). Hydrogenerator start / stop costs. Technical report, U.S. Department of the Interior, Technical Service Center.

Cimino, A., J. Horst, and F. Jenau (2020). Statistic based method for post-processing analysis in lifetime investigations of multi-factor aged winding insulation. In B. Németh (Ed.), Proceedings of the 21st International Symposium on High Voltage Engineering. ISH 2019. Lecture Notes in Electrical Engineering, Volume 598, Cham, pp. 825-837. Springer International 
Publishing.

Coffin, Jr, L. F. (1953). A study of the effects of cyclic thermal stresses on a ductile metal. Technical Report KAPL-853, Knolls Atomic Power Lab. https://www.osti.gov/biblio/4363016.

Cui, H. (2005). Accelerated temperature cycle test and coffin-manson model for electronic packaging. In Annual Reliability and Maintainability Symposium, 2005. Proceedings., pp. 556560.

Cygan, P. and J. R. Laghari (1990). Models for insulation aging under electrical and thermal multistress. IEEE Transactions on Electrical Insulation 25(5), 923-934.

Dixon, R. R. (1980). Thermal aging predictions from an arrhenus plot with only one data point. IEEE Transactions on Electrical Insulation EI15(4), 331-334.

E-Cigre (2009). Survey of hydrogenerator failures. Technical report, Working Group A1.10.

EPRI

(1984).

Hydropower reliability study. Technical Report EM-3435, Electric Power Research Institute. https://www.epri.com/research/products/EM3435.

Greisen, L. and J. Norlin (2016). The effects of variable operation on hydropower equipment with a focus on start/stop. Technical Report T152700-0391, HDR CEATI Report.

Hami, A. E., I. R. D. Delaux, and H. Grzeskowiak (2018). Fiabilité des systèmes mécatroniques de forte puissance 2 . ISTE Groupe Editions.

Istad, M., M. Runde, and A. Nysveen (2011). A review of results from thermal cycling tests of hydrogenerator stator windings. IEEE Transactions on Energy Conversion 26(3), 890-903.

Klamt, T., T. Hillmer, and F. Vannay (2011). Assessment of insulation condition of hydro generator stator bars after 40 years in service. In 2011 Electrical Insulation Conference (EIC)., pp. 244-248.

Kokko, V. I. J. (2010). Electrical ageing in lifetime estimation of hydroelectric generator stator windings. In The XIX International Conference on Electrical Machines - ICEM 2010, pp. $1-5$.

Kokko, V. I. J. (2011). Electro-thermal ageing in lifetime estimation of hydroelectric generator stator windings. In 8th IEEE Symposium on Diagnostics for Electrical Machines, Power Electronics Drives, pp. 294-299.

Kokko, V. I. J. (2012). Ageing due to thermal cycling by power regulation cycles in lifetime estimation of hydroelectric generator stator windings. In 2012 XXth International Conference on Electrical Machines, pp. 1559-1564.

M.Guerrero, L. M. and A. A. I.Rivera (2005). A degradation model of synchronous generator stator insulation. In Proceedings of the 37th Annual North American Power Symposium, 2005., pp. 281-286.
Milano, B. (2012). Technology review: Stator winding insulation life expectancy and start/stop related age. Technical Report T102700-0369, Bureau of Reclamation CEATI.

Milano, B. (2016). Hydrogenerator stator winding aging processes and the associated synergies. Combined Cycle journal.

Montanari, G. C. and L. Simoni (1993). Aging phenomenology and modeling. IEEE Transactions on Electrical Insulation 28(5), 755-776.

Morin, R., J. P. Novak, R. Bartnikas, and R. Ross (1995). Analysis of in-service aged stator bars. IEEE Transactions on Energy Conversion 10(4), 645-654.

Nilsson, O. and D. Sjelvgren (1997). Hydro unit start-up costs and their impact on the short term scheduling strategies of swedish power producers. IEEE Transactions on Power Systems 12(1), 38-44.

NXP (1998). Modified coffin-manson equation for af calculations. Technical Report 512-9337289, NXP Custumer Applications Support.

Savin, O., C. Badina, J. Baroth, S. Charbonnier, and C. Bérenguer (2020). Start and Stop Costs for Hydro Power Plants: A Critical Literature Review. In P. Baraldi, F. Di Maio, and E. Zio (Eds.), ESREL 2020 - PSAM 15 - 30th European Safety and Reliability Conference and 15th Probabilistic Safety Assessment and Management Conference, Venise (Virtual conference), Italy. Paper\# 4102.

Stone, G. C., J. F. Lyles, J. M. Braun, and C. L. Kaul (1991). A thermal cycling type test for generator stator winding insulation. IEEE Transactions on Energy Conversion 6(4), 707713.

Stone, G. C., M. Sasic, D. Dunn, and I. Culbert (2009). Recent problems experienced with motor and generator windings. In 2009 Record of Conference Papers - Industry Applications Society 56th Annual Petroleum and Chemical Industry Conference, pp. 1-9.

Sumereder, C. (2008). Statistical lifetime of hydro generators and failure analysis. IEEE Transactions on Dielectrics and Electrical Insulation 15(3), 678-685.

Sumereder, C. and H. Muhr (2005). Estimation of residual lifetime - theory and practical problems. In Höfler's Days. Elektroinstitut Milan Vidmar. , Seite von - bis: 04.01-04.06.

Verma, H. C., A. Baral, A. K. Pradhan, and S. Chakravorti (2017). A method to estimate activation energy of power transformer insulation using time domain spectroscopy data. IEEE Transactions on Dielectrics and Electrical Insulation 24(5), 3245-3253. 